Part I

First Steps 



\title{
1
}

\section{A View of Research}

\author{
Tony Greenfield
}

\section{Introduction}

Research, depending on your viewpoint, is:

- a quest for knowledge and understanding;

- an interesting, and perhaps useful, experience;

- a course for qualification;

- a career;

- a style of life;

- an essential process for commercial success;

- a way to improve human quality of life;

- an ego boost for you; and/or

- a justification for funds for your department and its continued existence.

To me, research is an art aided by skills of inquiry, experimental design, data collection, measurement and analysis, by interpretation, and by presentation. A further skill, which can be acquired and developed, is creativity or invention.

This book is mainly about the former set of skills, inquiry to presentation. Further useful topics are described, such as: how to find funds, how to protect your intellectual property and how to share and use the results when your research is concluded.

But first: a few words about the origin of this book. The first edition was inspired by the government's proposal in 1994 that all graduates who wish to study for doctorates should first take a one-year master's course in research methods. Whether or not you agree with this, you may agree that some notes for guidance of post-graduate research students would be useful. Many universities have followed the government's proposal and have created research methods courses. There is already a place for this book. Whether you are studying a master's course in research methods, or doing some research for a master's degree or a doctorate, you can be guided by this book. 
However, research is a big subject, and it would not be possible to write a single volume about it in any depth. This book is intended to be a general reference on all aspects of research methods and should be used as notes for guidance. Its content is intended to be fairly simple and easily intelligible by most readers. There are references to more substantive texts.

The many viewpoints and components of research methods persuaded me that several contributors would be needed. Fortunately, there are enough qualified people in universities, consultancy and industry who volunteered eagerly to write one or more chapters each. I asked them to write in a light style that could be read easily with a view to the reader picking up the general themes. I believe that between us we have achieved this but leave it now to you, the reader, to judge.

If there are parts that you don't understand, or that could be expressed more clearly, or if there are important omissions, please write to me or the publishers. Everything can be improved, especially a book, and your opinions will help us.

\section{Contents}

These notes for your guidance have been divided into seven sections, with several chapters in each. Look through the contents list and see how the topics have been grouped. You may feel that some of the chapters are not for you. For example: do you know how to use the library? Of course you do! But do you? I suspect that many people who believe that they know how to find the right text at the right time will be happily surprised to discover how much easier the task becomes when qualified guidance is given. Surely you will want to know how to find funds for your research, but 'Ethics? Ethics has nothing to do with my research', you might say. It has. It has something to do with all research. Read the chapter and learn.

You will run into difficulties. You will find problems of management, of resources, of people. There's a chapter telling you who can help. I suggest you read it before you meet those problems. There are chapters too on planning your work, about keeping documents, about examining your research process and keeping it on course.

There are several types of research and we have classified them as: clinical trials, laboratory and industrial experiments, agricultural experiments, and surveys. These may seem to be distinct but there is a general philosophy running through all of them, expressed in different ways by the different writers. You may think that because your research fits into one class of research, you can ignore the other three chapters in that section. Please make the effort to read those other three chapters. You will be stimulated to discover a new slant on your research.

Glance quickly at the section on data analysis and you may think "I can leave that until much later, when I have some data to analyse." Scientific method is about observing the world and collecting information so that you can understand the world better. The way in which you do this must surely depend on how you will process the information when you have collected it. The data you collect will depend on how you will analyse the data. Analysis is an essential feature of research, and you will make easier progress with your research the more you understand analysis. To some people it is hard and daunting. They would prefer to ignore it. To other people it is a challenge. Whichever is your viewpoint, make it a challenge and face it now. Honestly, the more you understand how you will analyse and interpret data, the better will be your planning and management of the way you collect it. The design of a good experiment depends on how the data from the experiment will be analysed. 
Mathematical modelling and simulation may seem to be remote from the reality that you want to investigate in your research. They are powerful tools in many situations. Social, medical, economic and political systems, as well as physical, chemical and biological ones, can be described as mathematical models which can then be used in computers to predict the behaviour of those systems under various conditions. This is a useful approach to many types of research. While you read through the examples included in Part V, keep asking yourself how each example may relate to your research project.

Whatever research you perform, you must present your results: in a thesis or dissertation, in reports and published papers and in stand-up talks or synchronous webinars to live audiences. There are many books about presentation, and some are recommended. Three chapters summarise the most useful points.

Other chapters offer good advice about how to buy and use computers and instrumentation, how to sample from populations and interview people, how to protect your intellectual property and how to progress in your career.

\section{Creativity}

Four chapters about creativity were added in the second edition. As a brief stimulant, I have preserved the following paragraphs.

Liam Hudson, in Contrary Imaginations: A Psychological Study of the English Schoolboy (Penguin, 1972), presents evidence that intelligence and creativity, as features of the human mind, are negatively correlated but that there are some fortunate people who are both intelligent and creative. The rare combination must be desirable in research, where we need both logic and imagination, where we need vision as well as the ability to plan and manage.

But what is creativity?

You are planning your research. You believe that every step on the way must be taken rationally. Indeed, that is the essence of most of this book: to guide you rationally through your work. But if you look at the most outstanding creative leaps in the history of science, you will see that they were all founded on an irrationality of thought. Well-known examples are: Watt's invention of the separate condenser for the steam engine as he strolled in the country, Poincare's theory of Fuchsian functions as he boarded a bus and Kekule's discovery of the benzene ring as he dozed by the fireside. So, be prepared to note any odd thought you might have at an unexpected time in an unexpected place. And don't discard unexpected results.

Just because something doesn't do what you planned it to do doesn't mean it's useless.

Thomas Alva Edison

Nevertheless, you can bring to bear some methods of intellectual discovery:

- Analogy: look for similarity between your problem and one for which the solution is known. Electrical circuits are envisioned as water flowing through tanks, pipes, pumps and valves; brain function is studied by comparison with computers. The more remote your analogy is from your problem, the more creative will be your solution.

- By parts: break the problem into a series of sub-problems which you hope will be more amenable to solution. 
- By random guesses: Edison used it extensively, and brainstorming is a modern version of it.

- Generalise: if a specific problem is baffling, write a general version of it; an algebraic model leads to simplified solutions compared with tackling complicated arithmetic head on.

- Add: a difficult problem may be resolved by adding an auxiliary sub-problem.

- Subtract: drop some of the complicating features of the original problem; this is a trick used in simulation to make it more tractable.

- Particularise: look for a special case with a narrower set of conditions, such as tackling a two-dimensional example of a three-dimensional problem.

- Stretch or contract: some problems are more tractable if their scale or the range of variables is altered.

- Invert: look at the problem from the opposite viewpoint; instead of "When will this train arrive at Oxford?" ask, "When will Oxford arrive at this train?"

- Restructure: in clinical studies, we do not ask if a treatment will cure a disease, but whether an inert treatment will fail to cure the disease.

- The method of Pappus: assume the problem is solved and calculate backwards.

- The method of Tertullus: assume a solution is impossible and try to prove why.

Check each of these approaches, asking yourself how you might bring it to bear on your problem. Then, if you need any more stimulation, read the following:

The Art of Scientific Investigation is a book by W.I.B. Beveridge published in 1950 but still, over half a century later, stimulating to read;

G. Polya's How to Solve It offers practical recipes; and

Arthur Koestler's The Act of Creation has a discussion of the working of the mind. 